\title{
Syndactyly-polydactyly-ear lobe syndrome
}

INSERM

\section{Source}

INSERM. (1999). Orphanet: an online rare disease and orphan drug data base. Syndactylypolydactyly-ear lobe syndrome. ORPHA:3259

A rare, genetic, cong enital limb malformation syndrome characterized by complete cutaneous syndactyly between toes 1-2, ulnar polydactyly (ranging from nubbins to an almost complete additional finger) and earlobe malformations. Additionally, abnormalities along the medial border of the foot are observed on X-ray imaging. There have been no further descriptions in the literature since 1976. 